OPEN ACCESS

Edited by:

Sinno Simons,

Erasmus Medical Center, Netherlands

Reviewed by:

Gerda Meijler,

Isala Women and Children's

Hospital, Netherlands

Fernando Cabañas,

Hospital Universitario Quirónsalud

Madrid, Spain

${ }^{*}$ Correspondence:

Manon J. N. L. Benders

M.Benders@umcutrecht.n

Specialty section:

This article was submitted to

Neonatology,

a section of the journal

Frontiers in Pediatrics

Received: 26 November 2020

Accepted: 14 April 2021

Published: 19 May 2021

Citation:

Tataranno ML, Vijlbrief DC, Dudink J and Benders MJNL (2021) Precision

Medicine in Neonates: A Tailored Approach to Neonatal Brain Injury.

Front. Pediatr. 9:634092.

doi: 10.3389/fped.2021.634092

\section{Precision Medicine in Neonates: A Tailored Approach to Neonatal Brain Injury}

\author{
Maria Luisa Tataranno, Daniel C. Vijlbrief, Jeroen Dudink and Manon J. N. L. Benders*
}

Department of Neonatology, Wilhelmina Children's Hospital/University Medical Center Utrecht, Utrecht University, Utrecht, Netherlands

Despite advances in neonatal care to prevent neonatal brain injury and neurodevelopmental impairment, predicting long-term outcome in neonates at risk for brain injury remains difficult. Early prognosis is currently based on cranial ultrasound (CUS), MRI, EEG, NIRS, and/or general movements assessed at specific ages, and predicting outcome in an individual (precision medicine) is not yet possible. New algorithms based on large databases and machine learning applied to clinical, neuromonitoring, and neuroimaging data and genetic analysis and assays measuring multiple biomarkers (omics) can fulfill the needs of modern neonatology. A synergy of all these techniques and the use of automatic quantitative analysis might give clinicians the possibility to provide patient-targeted decision-making for individualized diagnosis, therapy, and outcome prediction. This review will first focus on common neonatal neurological diseases, associated risk factors, and most common treatments. After that, we will discuss how precision medicine and machine learning (ML) approaches could change the future of prediction and prognosis in this field.

Keywords: personalized medicine, brain injury, intraventricular hemorrhage, stroke, newborn, preterm, artificial intelligence, precision medicine

\section{INTRODUCTION}

Despite enormous advances in neonatal care to prevent neonatal brain injury and future neurodevelopmental impairment, predicting long-term outcome in neonates at risk for brain injury remains difficult. Parents and families of newborns admitted to the NICU with brain injury inevitably face many unknowns. In the initial period after birth, their first question will usually be: "Will my baby survive?" immediately followed by other fundamental questions such as: "What kind of future can we expect for our child? And for us as a family?" or "Will my baby be able to walk? Will he/she go to school?"

Currently, prediction of outcome is based on developmental milestones measured at specific ages. Early prognosis is based on CUS, MRI, EEG, and/or general movements assessment (GMA) assessed during follow up visits. These methods' predictive power is based primarily on population data reflecting the general outcome in similar children. Thus, predicting the outcome in a specific individual (personalized prediction medicine) is not yet possible and is urgently needed. Estimating the most accurate prognosis, as early as possible, is essential to adequately inform the child's family and begin intervention therapy even before the onset of clinical symptoms, 
particularly given that the brain's plasticity is highest in the first few months after birth. An individualized approach to neonatal brain injury and neurologic-oriented precision medicine is warranted for fragile neonates, not only for outcome prediction but also for preventing or reducing neonatal brain injury and supporting decision-making. Perinatal conditions leading to brain injury in the neonatal period include hypoxia-ischemia, arterial ischemic stroke, and intraventricular hemorrhage and especially its complications [post-hemorrhagic ventricular dilatation (PHVD) and periventricular venous hemorrhagic infarction (PVHI)], primary causes of neonatal mortality, and life-long disabilities such as epilepsy and cerebral palsy $(1,2)$. It has become clear that there is a need for individual and precise information on the spectrum of risk factors, symptoms, early detection, type, and location of brain injury to design/initiate effective therapeutic and supportive strategies.

In a NICU, medical professionals are continuously trying to obtain as much information as possible on the patients in their care. Education and experience provide them with the skills to make the right decisions. However, the patient load is high. Furthermore, the human mind can only recall the outcome of the most recent or complicated case. Computer programs can approach human cognitive tasks. Thus, a possible approach to fulfill the needs of modern neonatology is developing new tools for a precision medicine approach based on large databases, and machine learning (ML) applied to neuromonitoring and neuroimaging data and genetic analysis and assays measuring multiple biomarkers (omics). A synergy of all these techniques and the use of automatic quantitative analysis could give clinicians the possibility to provide patient-targeted answers to parents' questions. Artificial intelligence can mimic human experience-based-learning with ML supervised by experts. ML learns from past experiences, identifies trends and patterns in data, and uses it to build a model or algorithm. These algorithms can be used afterwards to make predictions on new data as a supportive-decision making tool. ML models can be created from data where the outcome is known (supervised learning). Also, ML can be used to identify patterns in data without previous knowledge (unsupervised learning).

This review will first focus on common neonatal neurological diseases such as perinatal hypoxia-ischemia, perinatal ischemic stroke and intraventricular hemorrhage and their risk factors and most common treatments. Afterwards, we will focus on how precision medicine and ML approaches might accurately identify infants who will develop HIE and cerebral palsy. We will primarily discuss the newest (and with highest predictive value) clinical, neurophysiological, neuroimaging, and "omics" techniques, that in our opinion, could change the future of prediction and prognosis in this field. However, we are aware that the present review cannot be comprehensive of all the techniques in the field, therefore we chose to focus on a limited list where the first steps are already taken toward a more individualized neonatal care and a better prediction.

\section{Hypoxic-Ischemic Encephalopathy}

Hypoxic ischemic encephalopathy (HIE) is characterized by a disturbed neurologic function in the perinatal period, manifesting with an abnormal level of consciousness, seizures, respiratory insufficiency, and depressed tone and reflexes (3). Currently, the only effective treatment to reduce death or severe long-term neurological impairment is therapeutic hypothermia, which led to an increase in survival rate, with a persistent rate of death and disabilities around $16-30 \%(4,5)$. However, timing of intervention is a significant factor in improving outcome and treatment efficacy (6).

Multiple mechanisms are involved in brain injury pathogenesis, such as hypoxia-ischemia, inflammation, excitotoxicity, and oxidative stress (7). The degree and extent of injury and individual vulnerability depends on sex, genetic background, maturational age, and the extent of brain injury and the degree of brain development of particular regions at the moment of insult $(8,9)$. Antenatal conditions such as maternal infection/inflammation, intrauterine growth restriction in utero hypoxia can also influence and modulate vulnerability to brain injury (7). Furthermore, different stages of brain injury can be recognized, and, for each stage, different mechanisms are involved. This information is critical to program therapeutic interventions $(10,11)$. Recent findings and ongoing studies, using ML-based on big data and -omics approaches, suggest that by combining clinical, neurophysiological, neuroimaging, and metabolic/(epi)genetic data, it might be possible to identify infants who will develop NE and cerebral palsy accurately, shortly after birth $(12,13)$. This would allow early initiation of therapy. However, these methods are currently not yet available at the bedside.

\section{Perinatal Arterial Ischemic Stroke}

Perinatal arterial ischemic stroke (PAIS) is a relatively common (birth-prevalence in term and near-term newborns ranges from 6 to $17 / 100,000)(14)$ and a severe neurologic disorder affecting primarily term infants (15). The actual treatment is supportive; however, neuroprotective approaches have been developed and are currently under evaluation in clinical trials. Among them, therapeutic hypothermia, erythropoietin, and stem cell therapy showed promising results in pre-clinical and pilot studies (1618).

Sex (male), obstetrical conditions (first pregnancy, caesarean section), and perinatal complications such as perinatal hypoxia, and foetal/neonatal inflammatory state, are most commonly associated with neonatal stroke (19). In general, most studies emphasize the role of maternal/fetal infection/inflammation (20). Inherited or acquired prothrombotic status contributes minor to the PAIS (21). The cumulative perinatal risk factors increase the incidence dramatically (22). Other conditions, such as bacterial meningitis, hypoglycemia, and congenital heart disease, may also be involved as risk factors in PAIS development (23).

Few studies using ML have attempted to obtain reproducible automatic segmentation of the stroke lesion volumes, mainly in adults (24). A comparative study evaluating different segmentation (simple vs. complex ML) methods shows that high-level ML methods lead to significantly better segmentation results compared to the relatively simple classification methods. However, none of the methods could achieve results in the range of the human observer agreement (24). Thus, more studies 
are needed in this field since segmentation can help quantify the size and location of injury to test the efficacy of therapies and prognosis.

\section{Intraventricular Hemorrhage (IVH), Periventricular Hemorrhagic Infarction (PVHI) and Post-hemorrhagic Ventricular Dilatation (PVHD)}

Intraventricular hemorrhage (IVH) and its severe complications: PVHI and PVHD, are common conditions after premature birth and are frequently associated with mortality and adverse longterm neurodevelopmental outcome (25). Regarding treatment, IVH prevention bundles such as delayed cord clamping, minimal handling, midline head position, limiting the number of infusions, and frequent multidisciplinary assessments have emerged as essential tools for reducing IVH morbidity (26-29).

Most relevant risk factors are lower gestational age, absent antenatal steroid treatment, low Apgar scores, pneumothorax, early sepsis, inherited thrombophilia, and the use of inotropic drugs during the first days of life $(30,31)$. However, recently Tortora et al. (32) suggested that the congenital variation in the vascular architecture of subependymal veins might play a role in the pathogenesis of IVH, especially when other risk factors affecting the cerebral circulation occur. Another recent study demonstrated that the presence and expression of specific vascular endothelial growth factor (VEGF) genetic phenotypes were associated with higher incidence rates of IVH in extremely preterm newborns (33). Regarding the possibility to apply ML to diagnose or prevent consequences of IVH in preterm infants early, one study attempted to determine whether ML techniques would be able to identify specific clusters of risk factors with different probability estimates for severe neonatal morbidity (including IVH) in preterm infants, with promising results (34). However, there is still much room for improvement, and further studies on this field are needed before clinicians will be able to use these tools in daily practice. A first, fundamental step can be to build a big publicly available dataset of clinical data, CUS and MRI images, neurophysiological and biochemical/genetic data by which deep ML models can find more generalized features to improve their performance.

\section{THE ROLE OF PRECISION MEDICINE FOR "BRAIN ORIENTED CARE"}

Advances in neonatal care, specifically "brain oriented care," particularly the use of therapeutic hypothermia for the treatment of hypoxic-ischemic encephalopathy, paved the way for neuroprotection in newborns at risk for brain injury. A multidisciplinary team for "brain-oriented care" is warranted in the NICU to optimally implement such treatments (26) and provide tailored care. This team should include pediatric neurologists, neonatologists, and "brain-oriented" specialized nurses (26). Furthermore, specific protocols should be combined with neuroimaging (MRI) and neuromonitoring [video multichannel EEG and amplitude-integrated EEG, near infrared spectroscopy (NIRS)] (Figure 1). Moreover, laboratory support

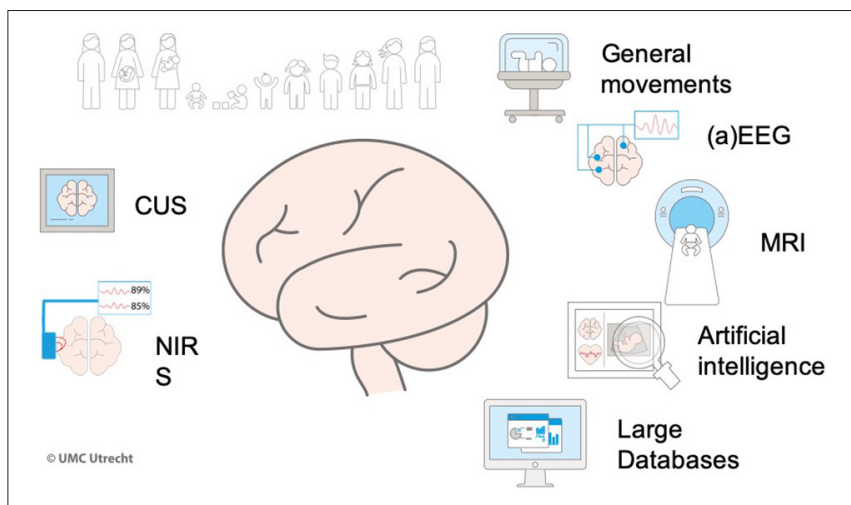

FIGURE 1 | Precision medicine for brain-oriented care.

for biomarkers, genetic and metabolic tests, and data scientists to analyze big data providing rapid algorithms for diagnosis and ad hoc treatments should be available. Dissemination of knowledge and research personnel and facilities is also warranted. Furthermore, genuinely personalized medicine is unlikely to be realized without the use of artificial intelligence (AI) (35) and ML. In neonatal neurology, ML is used to prevent brain injury from the continuous assessment of vital signs (36). Fairchild et al. (37) used a heart rate characteristic index (HRC index) from the first 28 days after birth in preterm infants and related this to neurodevelopmental outcome. They found an abnormal HRC to correlate with acute brain injury.

Much effort was made to develop automated seizure detection. When tested, all algorithms showed clinically relevant detection rates (38). Doyle et al. (39) and Malarvilli and Mesbah (40) used heart rate variability to detect seizures. Their model showed relevant results with sensitivity and specificity above $80 \%$. Karayiannis et al. (41) designed a trained neural network that was able to distinguish seizures from random infant movements based on video images. In the term infant, encephalopathy severity can be classified based on the EEG signal. Several attempted to grade the degree of abnormality in the EEG of a neonate with hypoxic-ischemic encephalopathy (42). The ML models were suitable as a clinical decision support tool to predict outcome after hypoxic-ischemic encephalopathy (43). Furthermore, evaluating the human connectome and its relation to normal and abnormal development in preterm and term infants is virtually impossible without ML (44). AI and ML are developing fields of research and will be introduced in clinical practice. Moreover, the interpretation of MRI images of term and preterm infants using ML can possibly individualize the outcome prognosis. ML understanding of EEG patterns can potentially guide medical treatment and the use of sedation. EEG and vital parameter analysis can explore sleeping patterns in preterm babies. The potential of automatically warning a caregiver when a baby is sleeping makes true personalized developmental care possible $(45,46)$.

The combination of clinical and ML tools trained on combined datasets of MRI, EEGs, clinical and biochemical/genetic data would hopefully help clinicians in 
providing all the treatments and support to mitigate the longterm effects of brain injury through the use of "brain orientedcare" during the whole admission and after discharge in a follow-up program.

Particularly, many efforts have been put into implementing MRI, EEG, GMs, Hammersmith Infant Neurological Examination (HINE) training for clinicians worldwide. However, achieving high education and gain experience in all these techniques is very hard in small centers. Thus, providing a decision support tool derived from ML algorithms can help every physician in decision-making, hopefully, a relevant improvement in long term outcome.

\section{MRI}

The use of magnetic resonance imaging (MRI), a non-invasive neuroimaging method, has revolutionized our knowledge of structural alterations to normal neural development leading to neurological impairment later in childhood (47). MRI can provide detailed info in vivo of the fetal and neonatal brain that cannot be obtained in any other imaging modality, helping clinicians define specific risk factors for neonatal brain injury (48).

Standard sequences (T1 and T2-weighted images) provide anatomic detail of the developing brain. They can detect brain injury and lesions linked to common neurological neonatal diseases: hypoxic-ischemic brain injury, perinatal arterial ischemic stroke, IVH-PVHI, infections of the central nervous system, and congenital cerebral malformations. Furthermore, advanced MRI sequences can be used in specific conditions to assess: brain metabolism (MR spectroscopy), the presence of hemosiderin (susceptibility-weighted images), microstructural integrity (diffusion tensor imaging), acute ischemic injury (diffusion-weighted images), cerebral veins and arteries (magnetic resonance angiography and venography), brain perfusion (arterial spin labeling), and function (restingstate functional MRI). Moreover, quantitative approaches can measure brain volumes of all different regions, quantify microstructural integrity and cortical development $(47,48)$, that are otherwise difficult to quantify by eye. Ad hoc protocols and specific methodologies have been developed in order to address the methodological challenges of the newborn population such as: sensitivity to motion, small brain size, different soft-tissue contrast and incomplete maturation of brain structures (47). Thus, the use of neonatal specific MRI post-processing tools is essential in order to obtain reliable results (47).

Recently, newly developed ML techniques have been applied to earlier acquired neonatal MRI databases to predict cognitive scores at 4 years (49). Similar techniques have been used to predict cognitive, and motor development in preterm infants based on the microstructure of white matter regions measured using diffusion tensor imaging (DTI) correlated with the Bayley Scales of Infant-Toddler Development (BSID-III), as well as to predict neurological outcome in patients with neonatal encephalopathy based on connectivity networks (5054). Moreover, deep learning-methods based on neonatal MRI and brain segmentation analysis have successfully automated classification of impaired brain maturation in full-term infants born with congenital heart disease and have provided insight into the pathogenesis of cerebellar dysplasia $(55,56)$. However, to optimize and refine the prognostic value of quantitative MRI techniques, it would highly be recommended to use standardized protocols, imaging modalities, and scan timing across centers (57).

\section{Quantitative MRI Techniques and Outcome Prognosis}

Quantitative brain MRI aims to offer objective and reliable measures of brain structure, function, and brain connectivity, in the normal and abnormal brain. The main aims of quantitative neonatal MRI are: the development of automatic algorithms for images interpretation (58), the detection, measurement, and characterization of "subtle" brain abnormalities/injuries $(59,60)$, and prediction of behavior, cognitive and motor long term outcome based on sophisticated algorithms (61). Quantitative MRI analysis is based on the use of multiple software packages capable of drawing together neuroimaging data processing routines from across, linking them together to implement end-toend processing and analytic solutions. These solutions not only lead to detailed mathematical and statistical results but also help to improve the reproducibility of measurements and reduce the post-processing duration (62).

Using ML approaches, quantitative analysis of brain morphometry showed significant deviations between different groups of preterm infants (with or without brain injury, extremely/moderately preterm) compared with full-term infants (47). A study comparing visual vs. quantitative MRI assessment of the thalami in infants with HIE showed that both approaches are needed since visual assessment alone can underestimate injury (63).

Automatic methods for brain volume and cortical morphology quantification, early as well as term equivalent age MRI, were good predictive tools of both motor and cognitive outcome at 2-3 years $(64,65)$. Furthermore, quantitatively assessed volume and location (frontal, parietal and temporal) of white matter injury, measured from MRIs, were predictive of motor outcome, while only frontal injury was predictive of cognition in a large group of preterm infants (66).

Diffusion MRI quantitative measures have also been related to later behavioral development in infants at risk for brain injury. Using automatic voxelwise analyses of DTI showed that WM microstructure in full-term newborns correlates with neurodevelopmental outcome at 2-years (67). Another study on neonatal connectome (detected using deep learning approaches) at birth showed its predictive value on the 2 -years cognitive outcome in both full-term and preterm infants (68), with connections involving the frontal lobe being the most important for classification. Smyser et al. (69), using a multivariate pattern analysis on resting-state functional MRIs from preterm infants compared to term controls, were able to estimate birth gestational age, and thus, brain maturity, with an accuracy of $84 \%$. 
Therefore, MRI advanced techniques provide direct information on brain morphology, structural brain connectivity, microstructural integrity of both gray and white matter, and also on cerebral function (47), giving indirect insights into molecular and cellular impairment in relation to brain injury. Thus, ML application to neonatal MRI, combined with other clinical, behavioral, and electrophysiological (see next paragraph) markers, can play an essential role in early diagnosis and prediction of neonatal brain injury and long-term impairment.

\section{CRANIAL ULTRASOUND (CUS)}

Ultrasound is a neonatal neuroimaging technique with several advantages over other neuroimaging techniques: it is considered less burdensome to the patient, requires no transport (e.g., to the MRI unit), or sedation, it can be performed at the bedside with acceptable disturbance to the infant. It can be initiated directly after birth and repeated if necessary (70). Ultrasound is seen as complementary to MRI because it still lacks several important neuroimaging features such as quantitative tissue analysis US. Furthermore, CUS is operator dependent, has a limited field of view, and variability across the quality of ultrasound machines. However, ultrasound technology developments are rapid, and ultrasound techniques such as elastography, ultrafast Doppler, contrast-enhanced ultrasound, and functional ultrasound are examples of techniques finding their way in routine neonatal care (71-75). Early and serial neuroimaging can provide valuable information about the timing and evolution of neonatal brain lesions in (pre-)term infants and enables visualization of (a)typical brain maturation (76).

Trained ultrasonographers, using modern ultrasound systems, can detect most neonatal hemorrhagic and ischemic brain lesions and major congenital as well as maturational anomalies (77). The use of different and higher frequency transducers (allowing submillimeter resolution) and additional acoustic windows (e.g., the mastoid fontanel) improved visualization, resulting in a more reliable detection of abnormalities (78). Doppler sonography of neonatal brain vessels enables the evaluation of intracranial blood flow velocities and the patency of both arteries and veins (e.g., to diagnose sinovenous thrombosis, arterial vessel occlusions) (78). Modern ultrasound machines have advanced Doppler modes, allowing visualization and quantification of low flows $(1-2 \mathrm{~cm} / \mathrm{s})$ in small vessels (100-200 $\mu \mathrm{m})(79)$.

\section{ML in Cerebral Ultrasound Techniques}

Both $2 \mathrm{D}$ and $3 \mathrm{D}$ ultrasound measurements are useful to study (a-)typical fetal and neonatal brain growth (80). For example, using 3D ultrasound measurements, ventricle volumes can be calculated to evaluate PHVD $(81,82)$. Machine learning can be applied to classify fetal brain ultrasound images as normal or abnormal, to detect non-typical brain growth, and detect general and focal brain injury (e.g., IVH) on neonatal CUS (83). ML is very effective in ultrasound analysis by modeling complex multidimensional data (84).

Ultrasound elastography is a relatively new technique that calculates tissue stiffness and is used to study (ab-)normal neonatal brain development. Two types of elastography are frequently used in neonatal CUS studies: 1. strain elastography (using external compression) and 2. shear wave elastography (using applied acoustic energy). Contrast-enhanced neonatal CUS (CE-CUS) is another promising technique to study microvasculature and cerebral vascular autoregulation in infants at risk for brain injury (e.g., infants with HIE, infants with congenital heart defects) $(85,86)$. Contrast-enhanced neonatal CUS uses injection of gas-filled microbubbles to study blood flow. CE-CUS also allows targeted (localized) medication delivery, which has potential future use for localized drug delivery in the brain (87). Another fast-developing ultrasound technique that holds promise for neonatal care is ultrafast doppler (UFD). Perinatal brain injury is commonly associated with inadequate brain perfusion, and UFD can be used to study microperfusion in detail (72). Combining continuous UFD with EEG could unravel the relationship between cortical electrical activity and perfusion (e.g., infants with HIE and seizures) (71).

Because of the large amount of data that the above-discussed ultrasound techniques generate, the integration (registration) with other imaging- and neuromonitoring techniques, and the observer dependence, ML will play a significant role in the future of neonatal CUS. ML will be needed to design clinical decision support algorithms that take several individualized variables into account.

\section{THE USE OF EEG/aEEG FOR PRECISION MEDICINE}

Newborns with vital instability or at risk of serious morbidity are admitted or transferred to the NICU, where vital parameters such as heart rate, blood pressure, oxygen saturation, and other measures are closely monitored. Additionally, brain function monitoring is essential. EEG can monitor brain function, giving continuous, long-time, and high-resolution data on cortical function. Thus, EEG is a crucial tool for precision medicine and a tailored approach to neonatal brain injury. EEG can be useful for precise diagnosis, evaluation of treatment efficacy, and prognosis. However, interpreting conventional EEG presents significant challenges to clinicians, and the most prominent current limitation is the need for expertise in the interpretation of EEG traces $(88,89)$. Thus, most NICU currently use the filtered and time-compressed EEG trace (aEEG). aEEG is a non-invasive, inexpensive, bedside tool that evaluates the brain functional status of the newborn, with a relatively easier interpretation based on background patterns recognition. This technique is a powerful tool for the prediction of neurodevelopmental outcome in both preterm and term neonates.

In the last decade, the automatic classification of EEG/aEEG has been developed (90). Different automatic algorithm classifications of background patterns, sleep-wake cycling, and seizure detection have been investigated using machine learning approaches (90). This paves the way for future incorporation of these algorithms in the daily neuromonitoring of newborns at 
risk. The first positive results were obtained to predict adverse seizure-related outcomes in critically ill children, albeit in a small number of patients (91). Recently, an ML algorithm for neonatal seizure recognition, ANSeR, was investigated in a randomised controlled trial and was found to be safe and able to detect neonatal seizures. However, it did not yet improve the identification of individual neonates with seizures (38).

\section{EEG/aEEG in HIE and Stroke Patients}

Term infants with NE need continuous monitoring of brain function using aEEG/EEG. The visual interpretation of the background pattern is a useful tool to monitor the recovery of cortical activity after HI injury (92, 93). Mainly, the normalization of the EEG after HI injury correlates with the outcome at 2 years of age. This process goes through different recovery steps from almost no electrical activity at the time of injury to the increasing number of bursts, toward a more continuous EEG with the appearance of sleep-wake stages (92, 94-96). For more personalized, brain-oriented care, visual EEG interpretation requires high expertise, and the evaluation incorporates multiple EEG characteristics such as continuity, amplitude, frequency, symmetry and synchrony, presence of sleep stages, and clinical information regarding gestational and postnatal age, differential diagnosis, administration of sedatives (94). This high expertise is not always continuously available in the NICU. Thus, the development of real-time, automated EEG analysis algorithms could be very valuable to assess cortical brain activity for clinical management, treatment evaluation, and prognosis. An important attempt was performed by Stevenson et al. (94) who developed a method for automatically grading the degree of EEG abnormality in neonates with HIE. EEG signals were post-processed based on EEG automated classification of abnormalities and assigned to one of four long-term EEG grades, resulting in $83 \%$ of EEG correct grading from 54 neonates. Lofhede et al. (90) managed to achieve 100\% correct classification when separating burst suppression EEG from all other EEG patterns and 93\% true positive classification when separating quiet sleep from the sleep stages in term infants. Burst suppression (BS) has also been associated with poor outcome (97), allowing for the analysis of interburst intervals (IBI) to be used as a feature that can assess the recovery of the infant's brain. New machines for cerebral functional monitoring incorporate automatic and real-time IBI calculation algorithm (IBI\%), making it available for the daily clinical management of these infants.

Furthermore, as already stated, the presence of seizures can be an indicator for neurodevelopmental outcome, as they can be caused by HIE (98) or perinatal stroke and can be detected through EEG data or clinical observation (92, 99-102). Automated seizure detection algorithms (SDA) are being developed with a reasonable performance compared to human expertise $(103,104)$ and with the advantage of being more objective, capable of analyzing long EEG recordings with low false detection rates and low missed seizures rates (105). Yet, currently available SDAs show significant limitations since seizures can be of short duration, low amplitude, and possibly migrate from channel to channel, with large intra and interpatient variability of seizure morphology and repetitive patterns (106). Furthermore, there is a high number of artifacts both of biological or technical origin mimicking seizures, that in combination with the low incidence of seizures and the wide range of normal rhythmic background activity (varying across gestational ages and post-natal ages) can reduce the power in seizure detection rates and increase the number of false-positive detections (107).

Analysis of the newborn's sleep-wake cycle (SWC) can also provide helpful insights on outcome in infants with brain injury (108). Regular SWC can distinguish those with proper brain integrity from those with HIE (109), both in full-term (96) and extremely preterms (110). Recent work suggested that decreased EEG delta-frequency power and longer periods of quiet sleep, and lower sleep-wake state entropy were also predictive of worse neonatal neurobehavioral scores (110). Despite many publications regarding $\mathrm{ML}$ and the development of automatic EEG/aEEG algorithms, there are still studies failing to establish the long-term predictive value of early aEEG/EEG characteristics in neonates (111).

A possible solution to allow a more comprehensive picture of the brain and thus yield more consistent, personalized, and reliable results should be the use of a combination of different measurements of brain dynamics, such as aEEG/EEG, NIRS, and MRI, together with the clinical neurologic examination. Nowadays, only a few studies on newborns have focused on the use of combined early aEEG/EEG and other cerebral monitoring techniques for the prediction of future outcome, with some promising results (112-116).

\section{EEG/aEEG Concerning IVH-PVHI}

Preterm infants are at risk for peri/intra-ventricular hemorrhage, especially during the transition phase, with associated adverse outcomes such as death or neurodevelopmental delay (117). Cerebral functional monitoring is essential to monitor preterm brain function during the first postnatal days. aEEG/EEG is the only effective bedside tool available in the $\operatorname{NICU}(118,119)$.

In extremely preterm infants, EEG/aEEG develops through to full term age showing increasing continuity of the background patterns, appearance of specific transient waveforms typical of prematurity, and the appearance of sleep-wake cycling (120). Assessing the infants' EEG recording can give insights into individual brain maturation in relation to GA and postnatal age (PNA), and serial recordings can help determine the timing and severity of brain injury and, thus, outcome prognosis in this high-risk group (120). Therefore, cerebral functional monitoring (CFM) using aEEG/EEG is critical for diagnosis, prognosis, and treatment in the newborn period (120). ML approaches have been used to analyze several clinical factors in 230 very preterm infants to predict the risk of intracerebral hemorrhage with good predictive ability achieved with different combinations of clinical and laboratory parameters (121). However, the developed models need to be tested further in new larger datasets before being used in the clinics.

Regarding neonatal seizures in preterm infants, these are a distinctive sign of neurological dysfunction in early life, and diagnosis is always challenging in this group. Clinical 


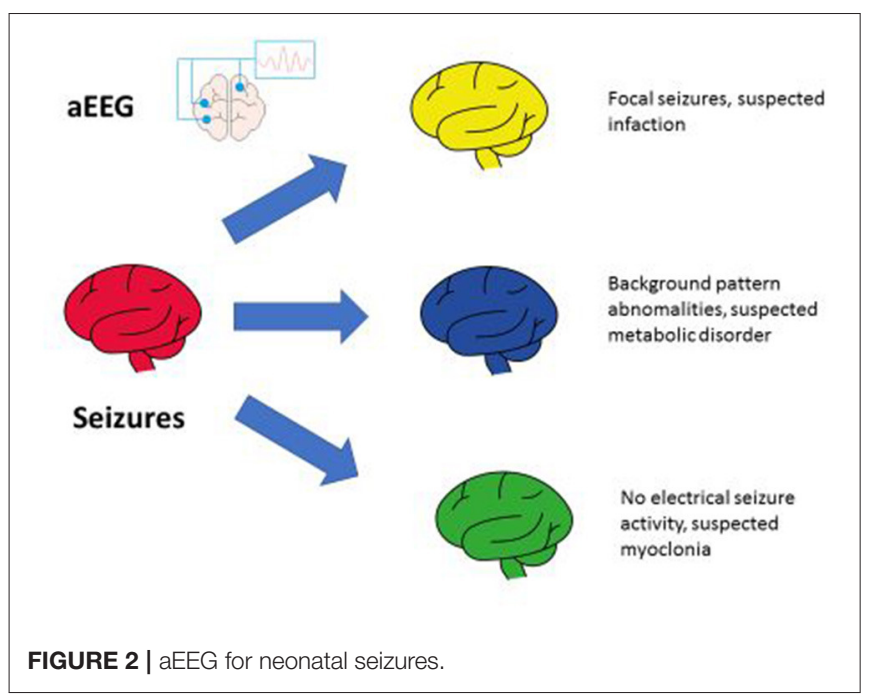

features, when present, can often provide valuable clues about etiology. However, the majority of neonatal seizures are subclinical. Conventional video EEG and aEEG represents the gold standard for diagnosis, but $\sim 15 \%$ of patients will require more sophisticated algorithms for diagnosis, including metabolic and genetic screening (110, 122, 123) (Figure 2). Currently, the standard recommendation is to monitor all neonates at high risk for seizures with long-term video-EEG (124) and to develop brain-oriented NICUs where neonatologists and pediatric neurologists would collaborate for early diagnosis and ad hoc treatments based on electroclinical phenotypes and etiology (125). Further steps should be taken in this direction in a multicenter/multicultural approach.

\section{NEAR INFRARED SPECTROSCOPY (NIRS)}

Near-infrared spectroscopy (NIRS) is a bedside technique that can provide valuable continuous information on neonatal cerebral blood flow, cerebral blood volume, and oxygen consumption (126-130). NIRS monitoring can help evaluate the balance between tissue oxygen delivery and consumption, allowing assessment of brain perfusion in critically-ill infants. Several studies have shown correlations between cerebral NIRS data and different neonatal conditions (e.g., anemia, hypotension, patent ductus arteriosus, hypoxia, hypocarbia, sepsis, HIE, stroke). The SafeBoosC studies have examined steering treatment on guideline-driven cerebral $\mathrm{rSO}_{2}$ monitoring in extremely premature infants to improve clinical outcomes (131). Cerebral NIRS monitoring has now become a useful addition to other monitoring tools in several neonatology departments. NIRS monitoring has been incorporated in several multimodal neuromonitoring approaches to assess neonatal cerebral functioning in the past decade (132). For example, NIRS is used to study cerebral vascular autoregulation, in which machine learning is applied to unravel the complex interactions between blood pressure, NIRS, and EEG data (114, 133-135). ML has several uses in NIRS data analysis such as artifact detection and correction, the quantitative evaluation of deep and shallow tissue layers, to analyze the high-frequency raw NIRS data signals to study in beat-to-beat variations within the NIRS signals and to cope with the large amount of data when multiple NIRS optodes are applied to the neonatal head $(136,137)$. We believe that with the help of ML, NIRS will be part of the multimodal neuromonitoring of infants at risk for brain injury to diagnose injury and steer treatment to prevent further injury and optimize neurodevelopment.

\section{GENERAL MOVEMENTS ASSESSMENT (GMs)}

Assessment of general movements (GMs) is a neurodevelopmental biomarker and evaluates the presence and quality of spontaneous movements originating in the brainstem (88). GMs begin in fetal life and are useful to build neural connectivity between motor and sensory systems. The presence of specific movement patterns such as cramped-synchronized at term equivalent age, together with the absence of fidgety movements at 3-5 months, are predictive of the development of cerebral palsy and other developmental problems (138). GMs has a sensitivity of $98 \%$ for cerebral palsy (CP) prediction and represent, together with neonatal MRI (86-89\% sensitivity) and the HINE (90\% sensitivity), the best predictive tool for detecting cerebral palsy before 5 months' of age and as early as by 3 months (139-142). Limitations to the broader use of GMs evaluation is the lack of trained clinicians and its subjective nature. Recently, an attempt to a more objective and cost-effective alternative based on the automatic video-based assessment of GMs has been made (143-145). In the paper by Orlandi et al. (144) retrospective videos were evaluated using automatic analysis, and GMs were classified as typical or atypical using different classification algorithms. This retrospective study showed up to $92 \%$ accuracy in predicting CP. More effort should be made in this direction to support clinicians in early diagnosis and treatment.

\section{HAMMERSMITH INFANT NEUROLOGICAL EXAMINATION (HINE)}

As previously mentioned, HINE can predict the development of cerebral palsy before 5 months of age with $90 \%$ sensitivity. There is evidence that the congruent combination of abnormal GMs trajectory, abnormal MRI and low HINE score is even more accurate than the individual technique alone $(139,140)$. The use of HINE plays a role also in the determination of severity of disability, a very important matter for parents or caregivers. Severity of motor outcome is difficult to predict before 2 years of age due to the rapid brain growth and re-organization in response to external stimuli and therapy. Thus, developing of motor skills but also the inconstant and changing presence of hypertonia (140), outcome prediction should always be discussed cautiously and based on standardized examinations. In particular, the following HINE cutoff scores predict the probable severity of motor outcome before 2 years of age: 50-73 Indicates likely unilateral CP (i.e., 95-99\% will walk), • <50 indicates likely 
bilateral CP. Furthermore, a score $<40$ at 3-6 months indicates the high chance of walking inability (142).

\section{LARGE DATABASES}

Many preterm infants are affected by the same neonatal neurological incidents. However, their internal variation in inflammatory response, environmental expositions, and (epi)genetics can influence the etiology and treatment response. Identification of individual risk factors and pathophysiological reactions can lead to targeted interventions. The use of electronic health records (EHR) has created vast amounts of clinical data on infant treatment. Utilizing the knowledge extracted from this data has the potential of providing individualized treatment plans (36). Large databases consist of a combination of individuals. These databases provide an insight into the epidemiology of neonatal disease with trends over time and the distribution of risk factors (146). Neonatal research networks, such as the NICHD and Vermont Oxford network, are collaborative networks that combine data from different hospitals. They can combine relevant information on relatively rare diseases affecting the newborn infant using large numbers. Shankaran et al. (147) described a cohort of 4,216 infants to assess post-hemorrhagic dilatation outcomes in extremely preterm infants. They were able to identify several predictors of neurodevelopmental impairment or death, such as surgery for retinopathy of prematurity, even though the incidence in a general NICU would only be a few cases.

Even more significant numbers can be obtained using nationwide databases. Most of this database research is limited to general mortality and morbidity trends for extreme preterm birth (43). Matsushita et al. (148) used the Neonatal Network of Japan database to identify risk factors for epilepsy at 3 years of age in VLBW infants. As only $1.7 \%$ of the cohort developed epilepsy, it would have been almost impossible to identify clinically relevant risk factors in a smaller cohort. Technological innovations make it possible to combine different information sources and provide information on a more detailed level. Clinically collected data from EHR with well-regulated, international, and privacy proof unrestricted access for researchers, such as the MIMIC-III and AmsterdamUMCdb database, and the increased availability of raw trial data could bring about a revolution in research on preterm neonates (149-152).

\section{(Epi)GENETICS AND OMICS-FUTURE}

The future concept of personalized medicine will be based on the idea that by using individual genetic/metabolic information, scientists may ensure the most appropriate treatments to the right patients-thus, "the right drug, at the right dose for the right person" (153). Genomics and epigenetics, i.e., the interaction between the genome and the environment, are changing the concept of clinical medicine, and this is particularly true in the field of neonatal neurology. Neonatologists and pediatricians have the unique chance to ensure that young patients derive maximal benefit from these new technologies.
In a recent study, epigenetic changes measured in blood leucocytes and analyzed using AI/ML techniques appeared to predict cerebral palsy accurately and provide crucial information on the pathogenesis of long-term disability (12).

Both genomics and epigenetics will provide clinicians new insights into the biological basis of health and disease (154). This will also lead to the sometimes-challenging choices of both the clinicians and the patients/families. Furthermore, understanding the mechanisms through which the environment exerts changes on genome expression will give new possibilities for new treatments by modulating gene expression and should be further investigated (155). In a not far-off future, knowledge of patients' genomes will help improving diagnosis and, through informed prediction of individual drug metabolism and responsiveness, the individualized selection of therapies.

Metabolomics can also provide valuable information for outcome prediction. Metabolites offer a unique signature potentially usable to predict neonatal diseases and evaluate disease progression and treatments' effect (156-158).

Metabolomic analysis performed in cord blood predicted the development of NE with an AUC of 0.67, with lactic acid and alanine as primary metabolite predictors for NE. When metabolomic analysis results were combined with clinical data, the AUC rose to 0.96 (13). Moreover, urinary metabolic spectra of extremely preterm infants early after birth were associated with moderately to severely abnormal cortical grey matter and white matter abnormalities at MRI performed at term equivalent age MRI (158). A growing number of studies had been published on this subject since metabolomic has the advantage of being rapid and non-invasive. Thus, metabolomics could be useful for monitoring early cellular injuries and cell death during perinatal insults. Therefore, it can pave the way for the early preventive measure to improve the neurodevelopmental outcome of the affected newborns.

\section{CONCLUSION}

The machine learning approach will provide more detailed information using AI for MRI, CUS, EEG, NIRS, and GM/HINE. An algorithm combining all techniques might give the best decision support tool for defining risk factors for brain injury or impaired brain development, therefore enabling better treatment and long-term outcome. In IVH, PAIS, and brain injury after HIE, MRI can improve personalized prognosis and treatment plan. EEG and aEEG provide more information on the brain than just a background pattern and seizure activity. Together with the HINE, GMs are the best predictive tools for early detecting cerebral palsy, and automatization of GMs classification can increase the rate of early diagnosis.

However, for the utilization of this potential, more expertise and the dissemination of knowledge is essential. Machine learning has the prospective of alleviating the task of bringing all the pieces of knowledge together. With the increasing amount of data on the infant in the NICU, it will become nearly impossible to interpret all these variables for a clinician and use it for the benefit of the individual patient. Artificial intelligence 
can fill (part of) the gap of knowledge and interpretation. Especially when genetics, epigenetics, biomarker research, and metabolomics will provide us with even more variables in the near future. As the era of AI, -ethics, and -omics is approaching, we must consider the Ethics. Will all babies benefit equally from precision medicine? Most efforts to personalised medicine require a high resource setting. MRI, continuous monitoring with ML interpretation, whole-genome sequencing, and even fully equipped NICU are not available in most parts of the world. Furthermore, to make an individual treatment plan and risk assessment, many assumptions are taken into account. They hold the risk of bias and even discrimination. Attempts to personalise treatment plans must include careful ethical consideration;

\section{REFERENCES}

1. Ferriero DM. Neonatal brain injury. N Engl J Med. (2004) 351:19851995. doi: 10.1056/NEJMra041996

2. Liu L, Oza S, Hogan D, Chu Y, Perin J, Zhu J, et al. Global, regional, and national causes of under-5 mortality in 2000-15: an updated systematic analysis with implications for the sustainable development goals. Lancet. (2016) 388:3027-35. doi: 10.1016/S0140-6736(16)31593-8

3. Executive summary: Neonatal encephalopathy and neurologic outcome, second edition. Report of the American college of obstetricians and gynecologists' task force on neonatal encephalopathy. Obstet Gynecol. (2014) 123:896-901. doi: 10.1097/01.AOG.0000445580.65983.d2

4. Shankaran S, Laptook AR, Pappas A, McDonald SA, Das A, Tyson JE, et al. Effect of depth and duration of cooling on death or disability at age 18 months among neonates with hypoxic-ischemic encephalopathy: a randomized clinical trial. JAMA. (2017) 318:5767. doi: $10.1001 /$ jama.2017.7218

5. Gunn AJ, Battin M. Towards faster studies of neonatal encephalopathy. Lancet Neurol. (2019) 18:21-22. doi: 10.1016/S1474-4422(18)30370-3

6. Wassink G, Davidson JO, Dhillon SK, Zhou K, Bennet L, Thoresen M, et al. Therapeutic hypothermia in neonatal hypoxic-ischemic encephalopathy. Curr Neurol Neurosci Rep. (2019) 19:2. doi: 10.1007/s11910-019-0916-0

7. Thornton C, Rousset CI, Kichev A, Miyakuni Y, Vontell R, Baburamani AA, et al. Molecular mechanisms of neonatal brain injury. Neurol Res Int. (2012) 2012:506320. doi: 10.1155/2012/506320

8. Johnston MV, Hagberg H. Sex and the pathogenesis of cerebral palsy. Dev Med Child Neurol. (2007) 49:74-8. doi: 10.1017/S0012162207000199.x

9. Vannucci SJ, Hagberg H. Hypoxia-ischemia in the immature brain. J Exp Biol. (2004) 207:3149-54. doi: 10.1242/jeb.01064

10. Gonzalez FF, Ferriero DM. Neuroprotection in the newborn infant. Clin Perinatol. (2009) 36:859-80. doi: 10.1016/j.clp.2009.07.013

11. van Velthoven CT, Kavelaars A, van Bel F, Heijnen CJ. Repeated mesenchymal stem cell treatment after neonatal hypoxia-ischemia has distinct effects on formation and maturation of new neurons and oligodendrocytes leading to restoration of damage, corticospinal motor tract activity, and sensorimotor function. J Neurosci. (2010) 30:960311. doi: 10.1523/JNEUROSCI.1835-10.2010

12. Bahado-Singh R, Vishweswaraiah S, Aydas B, Mishra NK, Guda C, Radhakrishna U. Deep learning/artificial intelligence and blood-based DNA epigenomic prediction of cerebral palsy. Int J Mol Sci. (2019) 20:2075. doi: 10.3390/ijms20092075

13. O’Boyle DS, Dunn WB, O'Neill D, Kirwan JA, Broadhurst DI, Hallberg B, et al. Improvement in the prediction of neonatal hypoxic-ischemic encephalopathy with the integration of umbilical cord metabolites and current clinical makers. J Pediatr. (2020) 229:175-81. doi: 10.1016/j.jpeds.2020.09.065

14. Darmency-Stamboul V, Cordier AG, Chabrier S. [Neonatal arterial ischemic stroke in term or near-term newborns: prevalence and risk factors]. Arch Pediatr. (2017) 24:9S3-11. doi: 10.1016/S0929-693X(17)30325-1 therefore, it should eventually be considered a decision support tool. Careful monitoring of infants in the perinatal period can potentially identify and improve neonatal brain injury treatment. "Precision medicine toward personalised care" is the aim for the near future.

\section{AUTHOR CONTRIBUTIONS}

MT, DV, and MB: conception/design, literature review, manuscript draft and review, critical review, and approval of final manuscript. JD: literature review, manuscript draft and review, critical review, and approval of final manuscript. All authors contributed to the article and approved the submitted version.

15. Martinez-Biarge M, Groenendaal F, Kersbergen KJ, Benders MJ, Foti F, Cowan FM, et al. MRI based preterm white matter injury classification: the importance of sequential imaging in determining severity of injury. PLoS ONE. (2016) 11:e0156245. doi: 10.1371/journal.pone.0156245

16. Harbert MJ, Tam EWY, Glass HC, Bonifacio SL, Haeusslein LA, Barkovich AJ, et al. Therapeutic hypothermia is correlated with seizure absence in perinatal stroke. Ann Neurol. (2011) 70:S113. doi: 10.1177/0883073811408092

17. Chevin M, Guiraut C, Maurice-Gelinas C, Deslauriers J, Grignon S, Sebire G. Neuroprotective effects of hypothermia in inflammatory-sensitized hypoxic-ischemic encephalopathy. Int J Dev Neurosci. (2016) 55:18. doi: 10.1016/j.ijdevneu.2016.09.002

18. Benders MJ, van der Aa, NE, Roks M, van Straaten HL, Isgum I, Viergever MA, et al. Feasibility and safety of erythropoietin for neuroprotection after perinatal arterial ischemic stroke. J Pediatr. (2014) 164:481-6. doi: 10.1016/j.jpeds.2013.10.084

19. Fluss J, Dinomais M, Chabrier S. Perinatal stroke syndromes: Similarities and diversities in aetiology, outcome and management. Eur J Paediatr Neurol. (2019) 23:368-83. doi: 10.1016/j.ejpn.2019.02.013

20. Bernson-Leung M, Boyd TK, Meserve EE, Danehy AR, Kapur K, Trenor $\mathrm{CC}$, et al. Placental pathology in neonatal stroke: a retrospective casecontrol study. J Pediatr. (2018) 195:39-47. doi: 10.1016/j.jpeds.2017. 11.061

21. Curtis C, Mineyko A, Massicotte P. Thrombophilia risk is not increased in children after perinatal stroke. Blood. (2017) 29:2793-800. doi: 10.1182/blood-2016-11-750893

22. Martinez-Biarge M, Cheong JLY, Diez-Sebastian J, Mercuri E, Dubowitz LMS, Cowan FM. Risk factors for neonatal arterial ischemic stroke: the importance of the intrapartum period. J Pediatr. (2016) 173:628. doi: 10.1016/j.jpeds.2016.02.064

23. Van der Aa NE, Dudink J, Benders MJNL, Govaert P, Van Straaten HLM, Porro GL, et al. Neonatal posterior cerebral artery stroke: clinical presentation, MRI findings, and outcome. Dev Med Child Neurol. (2013) 55:283-90. doi: 10.1111/dmcn.12055

24. Maier O, Schroder C, Forkert ND, Martinetz T, Handels H. Classifiers for ischemic stroke lesion segmentation: a comparison study. PLoS ONE. (2015) 10:e0145118. doi: 10.1371/journal.pone.0145118

25. Glass HC, Costarino AT, Stayer SA, Brett CM, Cladis F, Davis PJ. Outcomes for extremely premature infants. Anesth Analg. (2015) 120:133751. doi: 10.1213/ANE.0000000000000705

26. Glass HC, Ferriero DM, Rowitch DH, Shimotake TK. The neurointensive nursery: concept, development, and insights gained. Curr Opin Pediatr. (2019) 31:202-9. doi: 10.1097/MOP.0000000000000733

27. Schmid MB, Reister F, Mayer B, Hopfner RJ, Fuchs H, Hummler HD. Prospective risk factor monitoring reduces intracranial hemorrhage rates in preterm infants. Dtsch Arztebl Int. (2013) 110:489-96. doi: 10.3238/arztebl.2013.0489

28. Pineda RG, Neil J, Dierker D, Smyser CD, Wallendorf M, Kidokoro H, et al. Alterations in brain structure and neurodevelopmental outcome in preterm 
infants hospitalized in different neonatal intensive care unit environments. $J$ Pediatr. (2014) 164:52-60. doi: 10.1016/j.jpeds.2013.08.047

29. Chiriboga N, Cortez J, Pena-Ariet A, Makker K, Smotherman C, Gautam S, et al. Successful implementation of an intracranial hemorrhage (ICH) bundle in reducing severe ICH: a quality improvement project. J Perinatol. (2019) 39:143-51. doi: 10.1038/s41372-018-0257-x

30. Linder N, Haskin O, Levit O, Klinger G, Prince T, Naor N, et al. Risk factors for intraventricular hemorrhage in very low birth weight premature infants: a retrospective case-control study. Pediatrics. (2003) 111:E5905. doi: 10.1542/peds.111.5.e590

31. Ramenghi LA, Fumagalli M, Groppo M, Consonni D, Gatti L, Bertazzi PA, et al. Germinal matrix hemorrhage: intraventricular hemorrhage in very-lowbirth-weight infants the independent role of inherited thrombophilia. Stroke. (2011) 42:1889-93. doi: 10.1161/STROKEAHA.110.590455

32. Tortora D, Severino M, Malova M, Parodi A, Morana G, Sedlacik J, et al. Differences in subependymal vein anatomy may predispose preterm infants to GMH-IVH. Arch Dis Child Fetal Neonatal Ed. (2018) 103:F5965. doi: 10.1136/archdischild-2017-312710

33. Prasun P, Madan R, Puthuraya S, Subramanian D, Datta I, Kalra V, et al. Can functional polymorphisms in VEGF and MMP predict intraventricular hemorrhage in extremely preterm newborns? Dev Neurosci. (2018) 40:33743. doi: $10.1159 / 000493788$

34. Hamilton EF, Dyachenko A, Ciampi A, Maurel K, Warrick PA, Garite TJ. Estimating risk of severe neonatal morbidity in preterm births under 32 weeks of gestation. J Matern Fetal Neonatal Med. (2020) 33:7380. doi: 10.1080/14767058.2018.1487395

35. Mesko B. The role of artificial intelligence in precision medicine. Exp Rev Precision Med Drug Dev. (2017) 2:23941. doi: 10.1080/23808993.2017.1380516

36. Kumar N, Akangire G, Sullivan B, Fairchild K, Sampath V. Continuous vital sign analysis for predicting and preventing neonatal diseases in the twenty-first century: big data to the forefront. Pediatr Res. (2020) 87:21020. doi: 10.1038/s41390-019-0527-0

37. Fairchild KD, Sinkin RA, Davalian F, Blackman AE, Swanson JR, Matsumoto JA, et al. Abnormal heart rate characteristics are associated with abnormal neuroimaging and outcomes in extremely low birth weight infants. $J$ Perinatol. (2014) 34:375-9. doi: 10.1038/jp.2014.18

38. Pavel AM, Rennie JM, de Vries LS, Blennow M, Foran A, Shah DK, et al. A machine-learning algorithm for neonatal seizure recognition: a multicentre, randomised, controlled trial. Lancet Child Adolesc Health. (2020) 4:7409. doi: 10.1016/S2352-4642(20)30239-X

39. Doyle OM, Temko A, Marnane W, Lightbody G, Boylan GB. Heart rate based automatic seizure detection in the newborn. Med Eng Phys. (2010) 32:829-39. doi: 10.1016/j.medengphy.2010.05.010

40. Malarvili MB, Mesbah M. Newborn seizure detection based on heart rate variability. IEEE Trans Biomed Eng. (2009) 56:2594-603. doi: 10.1109/TBME.2009.2026908

41. Karayiannis NB, Xiong Y, Tao G, Frost JD Jr, Wise MS, Hrachovy RA, et al. Automated detection of videotaped neonatal seizures of epileptic origin. Epilepsia. (2006) 47:966-80. doi: 10.1111/j.1528-1167.2006.00571.x

42. Ahmed R, Temko A, Marnane W, Lightbody G, Boylan G. Grading hypoxic-ischemic encephalopathy severity in neonatal EEG using GMM supervectors and the support vector machine. Clin Neurophysiol. (2016) 127:297-309. doi: 10.1016/j.clinph.2015.05.024

43. Ambalavanan N, Carlo WA, Tyson JE, Langer JC, Walsh MC, Parikh NA, et al. Outcome trajectories in extremely preterm infants. Pediatrics. (2012) 130:e115-25. doi: 10.1542/peds.2011-3693

44. van den Heuvel MP, Kersbergen KJ, de Reus MA, Keunen K, Kahn RS, Groenendaal F, et al. The neonatal connectome during preterm brain development. Cereb Cortex. (2015) 25:3000-13. doi: 10.1093/cercor/bhu095

45. van den Hoogen A, Teunis CJ, Shellhaas RA, Pillen S, Benders M, Dudink J. How to improve sleep in a neonatal intensive care unit: a systematic review. Early Hum Dev. (2017) 113:78-86. doi: 10.1016/j.earlhumdev.2017.07.002

46. Ansari AH, De Wel O, Lavanga M, Caicedo A, Dereymaeker A, Jansen K, et al. Quiet sleep detection in preterm infants using deep convolutional neural networks. J Neural Eng. (2018) 15:066006. doi: 10.1088/1741-2552/aadc1f

47. Dubois J, Alison M, Counsell SJ, Hertz-Pannier L, Huppi PS, Benders M. MRI of the neonatal Brain: a review of methodological challenges and neuroscientific advances. J Magn Reson Imaging. (2020) 53:131843. doi: 10.1002/jmri.27192

48. Counsell SJ, Arichi T, Arulkumaran S, Rutherford MA. Fetal and neonatal neuroimaging. Handb Clin Neurol. (2019) 162:67103. doi: 10.1016/B978-0-444-64029-1.00004-7

49. Adeli E, Meng Y, Li G, Lin W, Shen D. Multi-task prediction of infant cognitive scores from longitudinal incomplete neuroimaging data. Neuroimage. (2019) 185:783-92. doi: 10.1016/j.neuroimage.2018.04.052

50. Schadl K, Vassar R, Cahill-Rowley K, Yeom KW, Stevenson DK, Rose J. Prediction of cognitive and motor development in preterm children using exhaustive feature selection and cross-validation of nearterm white matter microstructure. Neuroimage Clin. (2018) 17:66779. doi: 10.1016/j.nicl.2017.11.023

51. Ziv E, Tymofiyeva O, Ferriero DM, Barkovich AJ, Hess CP, Xu D. A machine learning approach to automated structural network analysis: application to neonatal encephalopathy. PLoS ONE. (2013) 8:e78824. doi: 10.1371/journal.pone.0078824

52. Kersbergen KJ, Leroy F, Isgum I, Groenendaal F, de Vries LS, Claessens NHP, et al. Relation between clinical risk factors, early cortical changes, and neurodevelopmental outcome in preterm infants. Neuroimage. (2016) 142:301-10. doi: 10.1016/j.neuroimage.2016.07.010

53. Keunen K, Benders MJ, Leemans A, Fieret-Van Stam PC, Scholtens LH, Viergever MA, et al. White matter maturation in the neonatal brain is predictive of school age cognitive capacities in children born very preterm. Dev Med Child Neurol. (2017) 59:939-46. doi: 10.1111/dmcn.13487

54. van Kooij BJ, de Vries LS, Ball G, van Haastert IC, Benders MJ, Groenendaal F, et al. Neonatal tract-based spatial statistics findings and outcome in preterm infants. AJNR Am J Neuroradiol. (2012) 33:18894. doi: 10.3174/ajnr.A2723

55. Ceschin R, Zahner A, Reynolds W, Gaesser J, Zuccoli G, Lo CW, et al. A computational framework for the detection of subcortical brain dysmaturation in neonatal MRI using 3D Convolutional Neural Networks. Neuroimage. (2018) 178:183-97. doi: 10.1016/j.neuroimage.2018.05.049

56. Claessens NHP, Breur J, Groenendaal F, Wosten-van Asperen RM, Stegeman $\mathrm{R}$, Haas F, et al. Brain microstructural development in neonates with critical congenital heart disease: an atlas-based diffusion tensor imaging study. Neuroimage Clin. (2019) 21:101672. doi: 10.1016/j.nicl.2019.101672

57. Chau V, Poskitt KJ, Dunham CP, Hendson G, Miller SP. Magnetic resonance imaging in the encephalopathic term newborn. Curr Pediatr Rev. (2014) 10:28-36. doi: 10.2174/157339631001140408120336

58. Morel B, Antoni G, Teglas JP, Bloch I, Adamsbaum C. Neonatal brain MRI: how reliable is the radiologist's eye? Neuroradiology. (2016) 58:18993. doi: 10.1007/s00234-015-1609-2

59. De Vries LS, Benders MJ, Groenendaal F. Should early cranial MRI of preterm infants become routine? Arch Dis Child Fetal Neonatal Ed. (2015) 100:284. doi: 10.1136/archdischild-2014-308077

60. Huppi PS, Dubois J. Diffusion tensor imaging of brain development. Semin Fetal Neonatal Med. (2006) 11:489-97. doi: 10.1016/j.siny.2006.07.006

61. Hinojosa-Rodriguez M, Harmony T, Carrillo-Prado C, Van Horn JD, Irimia A, Torgerson $\mathrm{C}$, et al. Clinical neuroimaging in the preterm infant: diagnosis and prognosis. Neuroimage Clin. (2017) 16:355-68. doi: 10.1016/j.nicl.2017.08.015

62. Dinov I, Lozev K, Petrosyan P, Liu Z, Eggert P, Pierce J, et al. Neuroimaging study designs, computational analyses and data provenance using the LONI pipeline. PLoS ONE. (2010) 5:e13070. doi: 10.1371/journal.pone.00 13070

63. Imai K, de Vries LS, Alderliesten T, Wagenaar N, van der Aa, N. E., Lequin $\mathrm{MH}$, et al. MRI changes in the thalamus and basal ganglia of full-term neonates with perinatal asphyxia. Neonatology. (2018) 114:25360. doi: 10.1159/000489159

64. Moeskops P, Isgum I, Keunen K, Claessens NHP, van Haastert IC, Groenendaal F, et al. Prediction of cognitive and motor outcome of preterm infants based on automatic quantitative descriptors from neonatal MR brain images. Sci Rep. (2017) 7:2163. doi: 10.1038/s41598-017-02307-w

65. Gui L, Loukas S, Lazeyras F, Huppi PS, Meskaldji DE, Borradori Tolsa C. Longitudinal study of neonatal brain tissue volumes in preterm infants and their ability to predict neurodevelopmental outcome. Neuroimage. (2019) 185:728-41. doi: 10.1016/j.neuroimage.2018.06.034 
66. Guo T, Duerden EG, Adams E, Chau V, Branson HM, Chakravarty $\mathrm{MM}$, et al. Quantitative assessment of white matter injury in preterm neonates: association with outcomes. Neurology. (2017) 88:614-22. doi: 10.1212/WNL.0000000000003606

67. Feng K, Rowell AC, Andres A, Bellando BJ, Lou X, Glasier CM, et al. Diffusion tensor MRI of white matter of healthy full-term newborns: relationship to neurodevelopmental outcomes. Radiology. (2019) 292:17987. doi: 10.1148/radiol.2019182564

68. Girault JB, Munsell BC, Puechmaille D, Goldman BD, Prieto JC, Styner M, et al. White matter connectomes at birth accurately predict cognitive abilities at age 2. Neuroimage. (2019) 192:145-55. doi: 10.1016/j.neuroimage.2019.02.060

69. Smyser CD, Dosenbach NU, Smyser TA, Snyder AZ, Rogers $\mathrm{CE}$, Inder $\mathrm{TE}$, et al. Prediction of brain maturity in infants using machine-learning algorithms. Neuroimage. (2016) 136:19. doi: 10.1016/j.neuroimage.2016.05.029

70. van Wezel-Meijler G, de Vries LS. Cranial ultrasound optimizing utility in the NICU. Curr Pediatr Rev. (2014) 10:16-27. doi: 10.2174/157339631001140408120106

71. Demene C, Baranger J, Bernal M, Delanoe C, Auvin S, Biran V, et al. Functional ultrasound imaging of brain activity in human newborns. Sci Transl Med. (2017) 9:eaah6756. doi: 10.1126/scitranslmed.aah6756

72. Demené C, Pernot M, Biran V, Alison M, Fink M, Baud O, et al. Ultrafast doppler reveals the mapping of cerebral vascular resistivity in neonates. $J$ Cereb Blood Flow Metab. (2014) 34:1009-17. doi: 10.1038/jcbfm.2014.49

73. Gennisson J-, Deffieux T, Fink M, Tanter M. Ultrasound elastography: principles and techniques. Diagn Interv Imaging. (2013) 94:487-95. doi: 10.1016/j.diii.2013.01.022

74. Hwang M, Jong RM, Herman S, Boss R, Riggs B, Tekes-Brady A, et al. Novel contrast-enhanced ultrasound evaluation in neonatal hypoxic ischemic injury: clinical application and future directions. J Ultrasound Med. (2017) 36:2379-86. doi: 10.1002/jum.14289

75. Macé E, Montaldo G, Cohen I, Baulac M, Fink M, Tanter M. Functional ultrasound imaging of the brain. Nat Methods. (2011) 8:6624. doi: 10.1038/nmeth.1641

76. Dudink J, Jeanne Steggerda S, Horsch S. State-of-the-art neonatal cerebral ultrasound: technique and reporting. Pediatr Res. (2020) 87(Suppl. 1):312. doi: 10.1038/s41390-020-0776-y

77. Plaisier A, Raets MMA, Ecury-Goossen GM, Govaert P, Feijen-Roon M, Reiss IKM, et al. Serial cranial ultrasonography or early MRI for detecting preterm brain injury? Arch Dis Child Fetal Neonatal Ed. (2015) 100:F293300. doi: 10.1136/archdischild-2014-306129

78. Raets MMA, Sol JJ, Govaert P, Lequin MH, Reiss IKM, Kroon AA, et al. Serial cranial US for detection of cerebral sinovenous thrombosis in preterm infants. Radiology. (2013) 269:879-86. doi: 10.1148/radiol.131 30401

79. Camfferman FA, Ecury-Goossen GM, La Roche JE, De Jong N, Van 't Leven W, Vos HJ, et al. Calibrating Doppler imaging of preterm intracerebral circulation using a microvessel flow phantom. Front Hum Neurosci. (2015) 8:1068. doi: 10.3389/fnhum.2014.01068

80. Koning IV, Roelants JA, Groenenberg IAL, Vermeulen MJ, Willemsen SP, Reiss IKM, et al. New ultrasound measurements to bridge the gap between prenatal and neonatal brain growth assessment. Am J Neuroradiol. (2017) 38:1807-13. doi: 10.3174/ajnr.A5278

81. Liu S, Wang Y, Yang X, Lei B, Liu L, Li SX, et al. Deep learning in medical ultrasound analysis: a review. Engineering. (2019) 5:26175. doi: 10.1016/j.eng.2018.11.020

82. Qiu W, Chen Y, Kishimoto J, de Ribaupierre S, Chiu B, Fenster A, et al. Automatic segmentation approach to extracting neonatal cerebral ventricles from 3D ultrasound images. Med Image Anal. (2017) 35:18191. doi: 10.1016/j.media.2016.06.038

83. Xie HN, Wang $\mathrm{N}, \mathrm{He}$ M, Zhang LH, Cai HM, Xian JB, et al. Using deep-learning algorithms to classify fetal brain ultrasound images as normal or abnormal. Ultrasound Obstet Gynecol. (2020) 56:57987. doi: 10.1002/uog. 21967

84. Brattain L, Telfer B, Dhyani M, Grajo J, Samir A. Machine learning for medical ultrasound: status, methods, and future opportunities. Abdom Radiol. (2018) 43:786-99. doi: 10.1007/s00261-018-1517-0
85. Hwang M, Sridharan A, Darge K, Riggs B, Sehgal C, Flibotte J, et al. Novel Quantitative contrast-enhanced ultrasound detection of hypoxic ischemic injury in neonates and infants: pilot study 1. J Ultrasound Med. (2019) 38:2025-38. doi: 10.1002/jum.14892

86. Knieling F, Rüffer A, Cesnjevar R, Regensburger AP, Purbojo A, Dittrich S, et al. Transfontanellar contrast-enhanced ultrasound for monitoring brain perfusion during neonatal heart surgery. Circ Cardiovasc Imaging. (2020) 13:e010073. doi: 10.1161/CIRCIMAGING.119.010073

87. Chandan R, Mehta S, Banerjee R. Ultrasound-responsive carriers for therapeutic applications. ACS Biomater Sci Eng. (2020) 6:4731-47. doi: 10.1021/acsbiomaterials.9b01979

88. Benninger KL, Inder TE, Goodman AM, Cotten CM, Nordli DR, Shah TA, et al. Perspectives from the society for pediatric research. neonatal encephalopathy clinical trials: developing the future. Pediatr Res. (2020) 89:74-84. doi: 10.1038/s41390-020-0859-9

89. Pisani F, Spagnoli C, Fusco C. EEG monitoring of the epileptic newborn. Curr Neurol Neurosci Rep. (2020) 20:6. doi: 10.1007/s11910-020-1027-7

90. Lofhede J, Thordstein M, Lofgren N, Flisberg A, Rosa-Zurera M, Kjellmer I, et al. Automatic classification of background EEG activity in healthy and sick neonates. J Neural Eng. (2010) 7:16007. doi: 10.1088/1741-2560/7/1/016007

91. Sanchez Fernandez I, Sansevere AJ, Gainza-Lein M, Kapur K, Loddenkemper T. Machine learning for outcome prediction in Electroencephalograph (EEG)-monitored children in the intensive care unit. J Child Neurol. (2018) 33:546-53. doi: 10.1177/0883073818773230

92. Murray DM, Boylan GB, Ryan CA, Connolly S. Early EEG findings in hypoxic-ischemic encephalopathy predict outcomes at 2 years. Pediatrics. (2009) 124:459. doi: 10.1542/peds.2008-2190

93. Toet MC, Hellstrom-Westas L, Groenendaal F, Eken P, de Vries LS. Amplitude integrated EEG 3 and 6 hours after birth in full term neonates with hypoxic-ischaemic encephalopathy. Arch Dis Child Fetal Neonatal Ed. (1999) 81:19. doi: 10.1136/fn.81.1.F19

94. Stevenson NJ, Korotchikova I, Temko A, Lightbody G, Marnane WP, Boylan GB. An automated system for grading EEG abnormality in term neonates with hypoxic-ischaemic encephalopathy. Ann Biomed Eng. (2013) 41:77585. doi: 10.1007/s10439-012-0710-5

95. Klebermass K, Olischar M, Waldhoer T, Fuiko R, Pollak A, Weninger M. Amplitude-integrated EEG pattern predicts further outcome in preterm infants. Pediatr Res. (2011) 70:102-8. doi: 10.1203/PDR.0b013e31821ba200

96. Zhang D, Ding H, Liu L, Hou X, Sun G, Li L, et al. The prognostic value of amplitude-integrated EEG in full-term neonates with seizures. PLoS ONE. (2013) 8:e78960. doi: 10.1371/journal.pone.0078960

97. Dereymaeker A, Matic V, Vervisch J, Cherian PJ, Ansari AH, De Wel $\mathrm{O}$, et al. Automated EEG background analysis to identify neonates with hypoxic-ischemic encephalopathy treated with hypothermia at risk for adverse outcome: a pilot study. Pediatr Neonatol. (2019) 60:508. doi: 10.1016/j.pedneo.2018.03.010

98. Kharoshankaya L, Stevenson NJ, Livingstone V, Murray DM, Murphy BP, Ahearne CE, et al. Seizure burden and neurodevelopmental outcome in neonates with hypoxic-ischemic encephalopathy. Dev Med Child Neurol. (2016) 58:1242-8. doi: 10.1111/dmcn.13215

99. Toet MC, Groenendaal F, Osredkar D, van Huffelen AC, de Vries LS. Postneonatal epilepsy following amplitude-integrated EEG-detected neonatal seizures. Pediatr Neurol. (2005) 32:2417. doi: 10.1016/j.pediatrneurol.2004.11.005

100. Fitzgerald MP, Massey SL, Fung FW, Kessler SK, Abend NS. High electroencephalographic seizure exposure is associated with unfavorable outcomes in neonates with hypoxic-ischemic encephalopathy. Seizure. (2018) 61:221-6. doi: 10.1016/j.seizure.2018.09.003

101. van Rooij LG, Toet MC, Osredkar D, van Huffelen AC, Groenendaal F, de Vries LS. Recovery of amplitude integrated electroencephalographic background patterns within 24 hours of perinatal asphyxia. Arch Dis Child Fetal Neonatal Ed. (2005) 90:245. doi: 10.1136/adc.2004. 064964

102. Weeke LC, Boylan GB, Pressler RM, Hallberg B, Blennow M, Toet MC, et al. Role of EEG background activity, seizure burden and MRI in predicting neurodevelopmental outcome in full-term infants with hypoxic-ischaemic encephalopathy in the era of therapeutic hypothermia. Eur J Paediatr Neurol. (2016) 20:855-64. doi: 10.1016/j.ejpn.2016.06.003 
103. Ansari AH, Cherian PJ, Caicedo A, Naulaers G, De Vos M, Van Huffel S. Neonatal seizure detection using deep convolutional neural networks. Int J Neural Syst. (2019) 29:1850011. doi: 10.1142/S0129065718500119

104. Greene BR, Boylan GB, Reilly RB, de Chazal P, Connolly S. Combination of EEG and ECG for improved automatic neonatal seizure detection. Clin Neurophysiol. (2007) 118:1348-59. doi: 10.1016/j.clinph.2007.02.015

105. Ansari AH, Cherian PJ, Caicedo Dorado A, Jansen K, Dereymaeker A, De Wispelaere L, et al. Weighted performance metrics for automatic neonatal seizure detection using multiscored EEG data. IEEE J Biomed Health Inform. (2018) 22:1114-23. doi: 10.1109/JBHI.2017.2750769

106. Mathieson S, Rennie J, Livingstone V, Temko A, Low E, Pressler $\mathrm{RM}$, et al. In-depth performance analysis of an EEG based neonatal seizure detection algorithm. Clin Neurophysiol. (2016) 127:2246-56. doi: 10.1016/j.clinph.2016.01.026

107. Mathieson SR, Stevenson NJ, Low E, Marnane WP, Rennie JM, Temko A, et al. Validation of an automated seizure detection algorithm for term neonates. Clin Neurophysiol. (2016) 127:156-68. doi: 10.1016/j.clinph.2015.04.075

108. Osredkar D, Toet MC, van Rooij LG, van Huffelen AC, Groenendaal F, de Vries LS. Sleep-wake cycling on amplitude-integrated electroencephalography in term newborns with hypoxic-ischemic encephalopathy. Pediatrics. (2005) 115:327-32. doi: 10.1542/peds.2004-0863

109. Shellhaas RA, Burns JW, Hassan F, Carlson MD, Barks JDE, Chervin RD. Neonatal sleep-wake analyses predict 18-month neurodevelopmental outcomes. Sleep. (2017) 40:zsx144. doi: 10.1093/sleep/zsx144

110. Wikstrom S, Pupp IH, Rosen I, Norman E, Fellman V, Ley D, et al. Early single-channel aEEG/EEG predicts outcome in very preterm infants. Acta Paediatr. (2012) 101:719-26. doi: 10.1111/j.1651-2227.2012.02677.x

111. Weeke LC, van Ooijen IM, Groenendaal F, van Huffelen AC, van Haastert IC, van Stam C, et al. Rhythmic EEG patterns in extremely preterm infants: classification and association with brain injury and outcome. Clin Neurophysiol. (2017) 128:2428-35. doi: 10.1016/j.clinph.2017.08.035

112. Goeral K, Urlesberger B, Giordano V, Kasprian G, Wagner M, Schmidt L, et al. Prediction of outcome in neonates with hypoxic-ischemic encephalopathy ii: role of amplitude-integrated electroencephalography and cerebral oxygen saturation measured by near-infrared spectroscopy. Neonatology. (2017) 112:193-202. doi: 10.1159/000468976

113. Hendrikx D, Smits A, Lavanga M, De Wel O, Thewissen L, Jansen K, et al. Measurement of neurovascular coupling in neonates. Front Physiol. (2019) 10:65. doi: 10.3389/fphys.2019.00065

114. Variane GFT, Chock VY, Netto A, Pietrobom RFR, Van Meurs KP. Simultaneous Near-Infrared Spectroscopy (NIRS) and AmplitudeIntegrated Electroencephalography (aEEG): dual use of brain monitoring techniques improves our understanding of physiology. Front Pediatr. (2019) 7:560. doi: 10.3389/fped.2019.00560

115. Tataranno ML, Alderliesten T, de Vries LS, Groenendaal F, Toet MC, Lemmers PM, et al. Early oxygen-utilization and brain activity in preterm infants. PLoS ONE. (2015) 10:e0124623. doi: 10.1371/journal.pone.0124623

116. Seki Y, Miyashita T, Kandori A, Maki A, Koizumi H. Simultaneous measurement of neuronal activity and cortical hemodynamics by unshielded magnetoencephalography and near-infrared spectroscopy. J Biomed Opt. (2012) 17:107001. doi: 10.1117/1.JBO.17.10.107001

117. Gill AW. Postnatal cardiovascular adaptation. Arch Dis Child Fetal Neonatal Ed. (2019) 104:F220-4. doi: 10.1136/archdischild-2017-314453

118. Pavlidis E, Lloyd RO, Boylan GB. EEG - a valuable biomarker of brain injury in preterm infants. Dev Neurosci. (2017) 39:23-35. doi: 10.1159/000456659

119. Hellstrom-Westas L, Rosen I. Electroencephalography and brain damage in preterm infants. Early Hum Dev. (2005) 81:255-61. doi: 10.1016/j.earlhumdev.2005.01.006

120. O'Toole JM, Boylan GB. Quantitative preterm EEG analysis: the need for caution in using modern data science techniques. Front Pediatr. (2019) 7:174. doi: 10.3389/fped.2019.00174

121. Turova V, Sidorenko I, Eckardt L, Rieger-Fackeldey E, FelderhoffMüser U, Alves-Pinto A, et al. Machine learning models for identifying preterm infants at risk of cerebral hemorrhage. PLOS ONE. (2020) 15:e0227419. doi: 10.1371/journal.pone.0227419

122. Ramantani G, Schmitt B, Plecko B, Pressler RM, Wohlrab G, KlebermassSchrehof K, et al. Neonatal seizures-are we there yet? Neuropediatrics. (2019) 50:280-93. doi: 10.1055/s-0039-1693149
123. Jarjour IT. Neurodevelopmental outcome after extreme prematurity: a review of the literature. Pediatr Neurol. (2015) 52:143-52. doi: 10.1016/j.pediatrneurol.2014.10.027

124. Shellhaas RA, Chang T, Tsuchida T, Scher MS, Riviello JJ, Abend NS, et al. The American clinical neurophysiology society's guideline on continuous electroencephalography monitoring in neonates. J Clin Neurophysiol. (2011) 28:611-7. doi: 10.1097/WNP.0b013e31823e96d7

125. Vilan A, Mendes Ribeiro J, Striano P, Weckhuysen S, Weeke LC, Brilstra E, et al. A Distinctive ictal amplitude-integrated electroencephalography pattern in newborns with neonatal epilepsy associated with KCNQ2 mutations. Neonatology. (2017) 112:387-93. doi: 10.1159/000478651

126. Balegar KK, Stark, Michael J, Briggs N, Andersen CC. Early cerebral oxygen extraction and the risk of death or sonographic brain injury in very preterm infants. J Pediatr. (2014) 164:475-80. doi: 10.1016/j.jpeds.2013.10.041

127. Toet MC, Lemmers PMA. Brain monitoring in neonates. Early Hum Dev. (2008) 85:77-84. doi: 10.1016/j.earlhumdev.2008.11.007

128. van Bel F, Mintzer JP. Monitoring cerebral oxygenation of the immature brain : a neuroprotective strategy? Pediatr Res. (2018) 84:159-64. doi: 10.1038/s41390-018-0026-8

129. Korček P, Stranák Z, Širc J, Naulaers G. The role of near-infrared spectroscopy monitoring in preterm infants. J Perinatol. (2017) 37:10707. doi: 10.1038/jp.2017.60

130. Escourrou G, Renesme L, Zana E, Rideau A, Marcoux MO, Lopez E, et al. How to assess hemodynamic status in very preterm newborns in the first week of life? J Perinatol. (2017) 37:987-93. doi: 10.1038/jp.2017.57

131. Hyttel-Sorensen S, Austin T, van Bel F, Benders M, Claris O, Dempsey $\mathrm{E}$, et al. A phase II randomized clinical trial on cerebral nearinfrared spectroscopy plus a treatment guideline versus treatment as usual for extremely preterm infants during the first three days of life (SafeBoosC): study protocol for a randomized controlled trial. Trials. (2013) 14:120. doi: 10.1186/1745-6215-14-120

132. Ter Horst HJ, Verhagen EA, Keating P, Bos AF. The relationship between electrocerebral activity and cerebral fractional tissue oxygen extraction in preterm infants. Pediatr Res. (2011) 70:384-88. doi: 10.1203/PDR.0b013e3182294735

133. Smet DD, Vanderhaegen J, Naulaers G, Huffel SV. New measurements for assessment of impaired cerebral autoregulation using near-infrared spectroscopy. Adv Exp Med Biol. (2009) 645:273-78. doi: 10.1007/978-0-387-85998-9_41

134. Caicedo A, De Smet D, Vanderhaegen J, Naulaers G, Wolf M, Lemmers P, et al. Impaired cerebral autoregulation using near-infrared spectroscopy and its relation to clinical outcomes in premature infants. Adv Exp Med Biol. (2011) 701:233-9. doi: 10.1007/978-1-4419-7756-4_31

135. Hendrikx D, Thewissen L, Smits A, Naulaers G, Allegaert K, Van Huffel S, et al. Nonlinear transfer entropy to assess the neurovascular coupling in premature neonates. Adv Exp Med Biol. (2020) 1232:117. doi: 10.1007/978-3-030-34461-0_2

136. Di Lorenzo R, Pirazzoli L, Blasi A, Bulgarelli C, Hakuno Y, Minagawa $\mathrm{Y}$, et al. Recommendations for motion correction of infant fNIRS data applicable to multiple data sets and acquisition systems. NeuroImage. (2019) 200:511-27. doi: 10.1016/j.neuroimage.2019. 06.056

137. Funane T, Atsumori H, Katura T, Obata AN, Sato H, Tanikawa $\mathrm{Y}$, et al. Quantitative evaluation of deep and shallow tissue layers' contribution to fNIRS signal using multi-distance optodes and independent component analysis. NeuroImage. (2014) 85:150-65. doi: 10.1016/j.neuroimage.2013.02.026

138. Kwong AKL, Fitzgerald TL, Doyle LW, Cheong JLY, Spittle AJ. Predictive validity of spontaneous early infant movement for later cerebral palsy: a systematic review. Dev Med Child Neurol. (2018) 60:480-9. doi: 10.1111/dmcn.13697

139. Bosanquet M, Copeland L, Ware R, Boyd R. A systematic review of tests to predict cerebral palsy in young children. Dev Med Child Neurol. (2013) 55:418-26. doi: 10.1111/dmcn. 12140

140. Romeo DM, Ricci D, Brogna C, Mercuri E. Use of the hammersmith infant neurological examination in infants with cerebral palsy: a critical review of the literature. Dev Med Child Neurol. (2016) 58:240-5. doi: $10.1111 /$ dmcn. 12876 
141. Ashwal S, Russman BS, Blasco PA, Miller G, Sandler A, Shevell M, et al. Practice parameter: diagnostic assessment of the child with cerebral palsy: report of the Quality Standards Subcommittee of the American Academy of Neurology and the Practice Committee of the Child Neurology Society. Neurology. (2004) 62:851-63. doi: 10.1212/01.WNL.0000117981.35364.1B

142. Novak I, Morgan C, Adde L, Blackman J, Boyd RN, Brunstrom-Hernandez J, et al. Early, accurate diagnosis and early intervention in cerebral palsy: advances in diagnosis and treatment. JAMA Pediatr. (2017) 171:897907. doi: 10.1001/jamapediatrics.2017.1689

143. Marchi V, Hakala A, Knight A, D'Acunto F, Scattoni ML, Guzzetta A, et al. Automated pose estimation captures key aspects of General Movements at eight to 17 weeks from conventional videos. Acta Paediatr. (2019) 108:181724. doi: 10.1111/apa.14781

144. Orlandi S, Raghuram K, Smith CR, Mansueto D, Church P, Shah V, et al. Detection of atypical and typical infant movements using computer-based video analysis. Annu Int Conf IEEE Eng Med Biol Soc. (2018) 2018:3598601. doi: 10.1109/EMBC.2018.8513078

145. Philippi H, Karch D, Kang KS, Wochner K, Pietz J, Dickhaus $\mathrm{H}$, et al. Computer-based analysis of general movements reveals stereotypies predicting cerebral palsy. Dev Med Child Neurol. (2014) 56:960-7. doi: $10.1111 / \mathrm{dmcn} .12477$

146. Yeo KT, Thomas R, Chow SS, Bolisetty S, Haslam R, Tarnow-Mordi W, et al. Improving incidence trends of severe intraventricular haemorrhages in preterm infants $<32$ weeks gestation: a cohort study. Arch Dis Child Fetal Neonatal Ed. (2020) 105:145-50. doi: 10.1136/archdischild-2018-316664

147. Shankaran S, Bajaj M, Natarajan G, Saha S, Pappas A, Davis AS, et al. Outcomes following post-hemorrhagic ventricular dilatation among extremely low gestational age infants. J Pediatr. (2020) S0022-3476:309793. doi: 10.1016/j.jpeds.2020.07.080

148. Matsushita Y, Sakai Y, Torio M, Inoue H, Ochiai M, Yasuoka K, et al. Association of perinatal factors of epilepsy in very low birth weight infants, using a nationwide database in Japan. J Perinatol. (2019) 39:14729. doi: 10.1038/s41372-019-0494-7

149. Sandfort V, Johnson AEW, Kunz LM, Vargas JD, Rosing DR. Prolonged elevated heart rate and 90-day survival in acutely Ill patients: data from the MIMIC-III database. J Intensive Care Med. (2019) 34:6229. doi: $10.1177 / 0885066618756828$

150. Saeed M, Villarroel M, Reisner AT, Clifford G, Lehman L, Moody G, et al. Multiparameter intelligentmonitoring in intensive care II: a public- access intensive care unit database. Critic Care Med. (2011) 39:95260. doi: 10.1097/CCM.0b013e31820a92c6

151. Shah PS, Kusuda S, Håkansson S, Reichman B, Lui K, Lehtonen L, et al. Neonatal outcomes of very preterm or very low birth weight triplets. Pediatrics. (2018) 142:e20181938. doi: 10.1542/peds.2018-1938

152. AmsterdamUMCdb. Available online at: https://www. amsterdammedicaldatascience.nl. (accessed Oct 15, 2020).

153. Feero WG, Guttmacher AE. Genomics, personalized medicine, and pediatrics. Acad Pediatr. (2014) 14:14-22. doi: 10.1016/j.acap.2013.06.008

154. Genomes Project Consortium, Abecasis GR, Auton A, Brooks LD, DePristo MA, Durbin RM, et al. An integrated map of genetic variation from 1,092 human genomes. Nature. (2012) 491:56-65. doi: 10.1038/nature 11632

155. Suva ML, Riggi N, Bernstein BE. Epigenetic reprogramming in cancer. Science. (2013) 339:1567-70. doi: 10.1126/science.1230184

156. Sarafidis K, Begou O, Deda O, Gika H, Agakidis C, Efstathiou N, et al. Targeted urine metabolomics in preterm neonates with intraventricular hemorrhage. J Chromatogr B Analyt Technol Biomed Life Sci. (2019) 1104:240-8. doi: 10.1016/j.jchromb.2018.11.024

157. Pineiro-Ramos JD, Nunez-Ramiro A, Llorens-Salvador R, Parra-Llorca A, Sanchez-Illana A, Quintas G, et al. Metabolic phenotypes of hypoxicischemic encephalopathy with normal vs. pathologic magnetic resonance imaging outcomes. Metabolites. (2020) 10:109. doi: 10.3390/metabo10030109

158. Tataranno ML, Perrone S, Longini M, Coviello C, Tassini M, Vivi A, et al. Predictive role of urinary metabolic profile for abnormal MRI score in preterm neonates. Dis Markers. (2018) 2018:4938194. doi: 10.1155/2018/4938194

Conflict of Interest: The authors declare that the research was conducted in the absence of any commercial or financial relationships that could be construed as a potential conflict of interest.

Copyright (c) 2021 Tataranno, Vijlbrief, Dudink and Benders. This is an open-access article distributed under the terms of the Creative Commons Attribution License (CC $B Y)$. The use, distribution or reproduction in other forums is permitted, provided the original author(s) and the copyright owner(s) are credited and that the original publication in this journal is cited, in accordance with accepted academic practice. No use, distribution or reproduction is permitted which does not comply with these terms. 